\title{
Clinical examination of the Astra Tech Implant System over 5-year period in our department
}

Maiko Yamada, Shin Ogura; Division of Oral Implant, The Nippon Dental University Hospital

Background:

Our department started using the Astra Tech Implant System in June 2010 . Here, we report a clinical study we carried out regarding implant placement cases handled over the past 5 years.

Material and Methods:

Subjects included 480 cases (1090 implants) of implant placement surgery performed over the past 5 years from June 2010 to May 2015 at our department.

We analyzed the following criteria;

(I) gender,

(2) average age when the patient had placement surgery performed,

(3) the details of the case,

(4) location of implant,

(5) the kind of implant used,

(6) the survival rate.

Results:

(I) The cohort included 208 male cases and 272 female cases.

(2) The average age when the patient had placement surgery performed was $53.5 \pm 14$.3years old overall. (male:54.8 \pm | 3.7years old, female: $52.5 \pm \mid 3$. lyears old)

(3) The details of the case,

\begin{tabular}{|c|c|c|}
\hline & numbers & cases \\
\hline maxilla & 470 & 208 \\
\hline mandible & 620 & 272 \\
\hline total & 1090 & 480 \\
\hline
\end{tabular}

(4) Location of implants

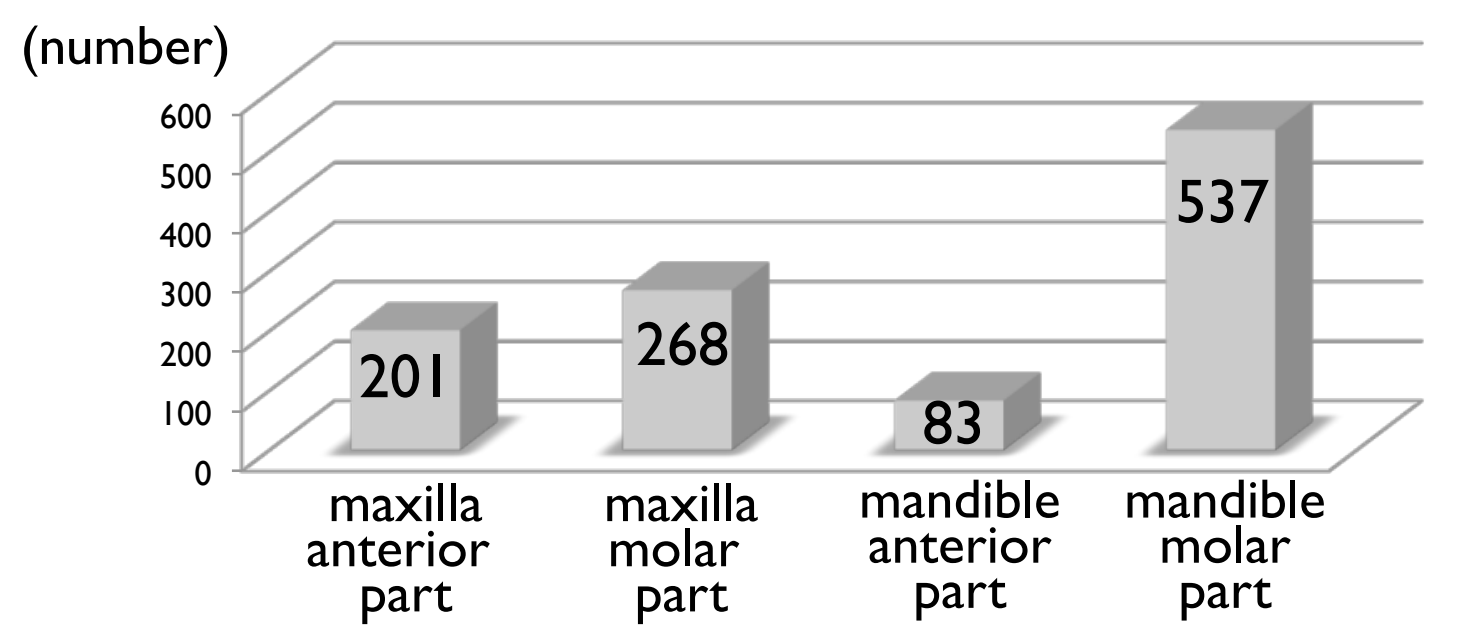

(5) The kind of implant used,
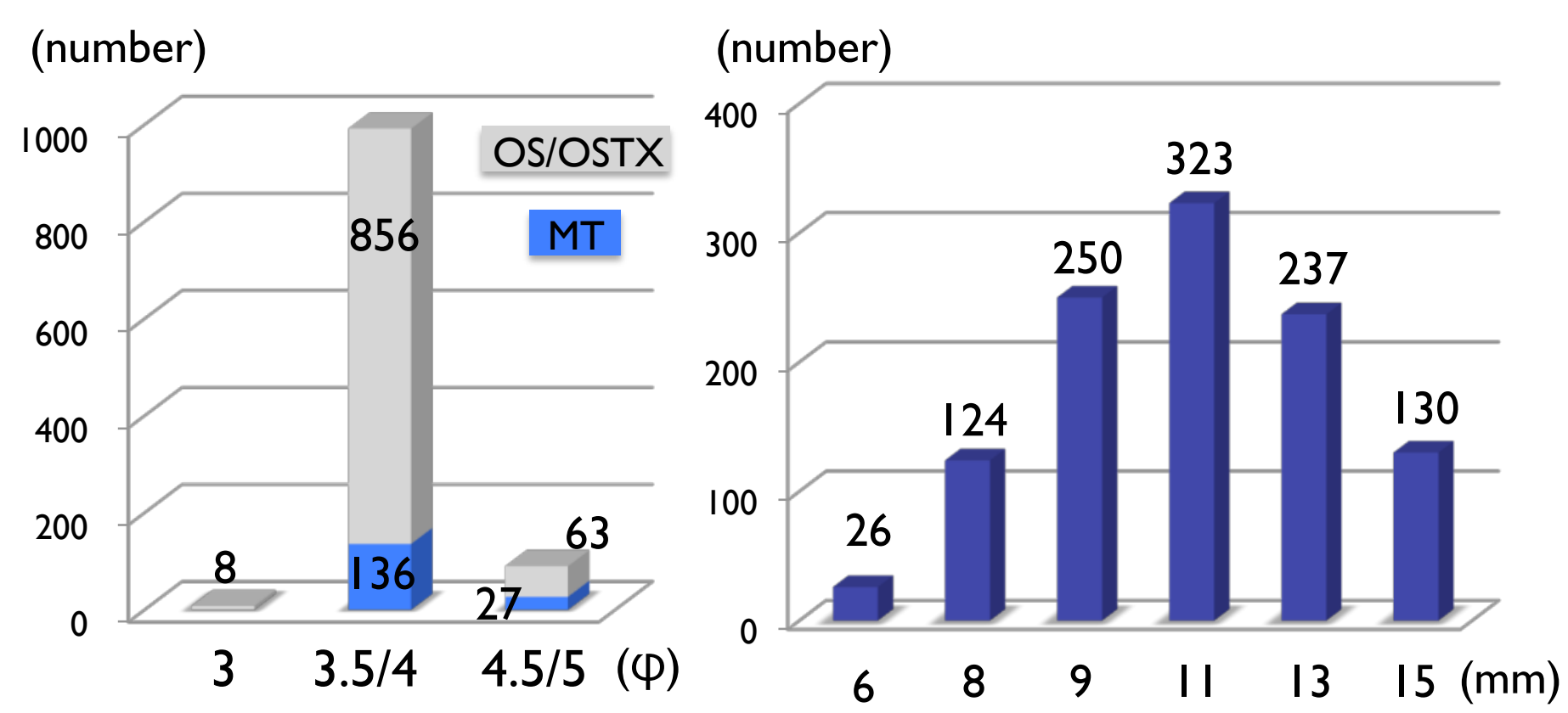

(6) The survival rate.

\begin{tabular}{|c|c|}
\hline & survival rate $(\%)$ \\
\hline maxilla & $2 / 470(99.6)$ \\
\hline mandible & $13 / 620(97.9)$ \\
\hline total & $15 / 1090(98.6)$ \\
\hline
\end{tabular}

The lengths of lost implants ranged from $9 \mathrm{~mm}$ to $15 \mathrm{~mm}$, with 6 lost before loading and 9 lost after loading.

\section{Discussion and Conclusion:}

Here, we performed a clinical analysis of the 5-year period over which our group has used the Astra Tech Implant System.

Although we reported long-term observation date for implants featuring surface treatments from other vendors, the results presented are consistent and likely to be useful for further investigation. However, a comparison remains difficult due to the short research period used in this analysis and more long-term analysis is planned for future studies. 